\title{
ROBERT MORRIS Y EL PRESENTE CONTÍNUO EN LA IMAGEN DEL LABERINTO DE PONTEVEDRA
}

Data recepción: 2013/06/12

Xosé Antón Castro Fernández

Data aceptación: 2013/09/24

Universidade de Vigo

Contacto autor: xacastro@uvigo.es

\section{RESUMEN}

El autor hace un análisis del Laberinto de Pontevedra, de Robert Morris, uno de los artistas fundamentales del panorama internacional en los últimos cincuenta años, teniendo en cuenta las coordenadas estéticas que han definido el trabajo de aquél -coordenadas decisivas en la transformación de la escultura de la modernidad a la postmodernidad- desde sus implicaciones en el minimalismo y el land art, sin olvidar la singularidad del nuevo contexto en el que fue invitado a trabajar, marcado por una fuerte carga cultural de origen prehistórico y por la estética del granito.

Palabras clave: Robert Morris, laberinto, Pontevedra, land art

\section{ABSTRACT}

The author provides an analysis of the Labyrinth of Pontevedra by Robert Morris, one of the most important artists on the international scene of the last 50 years. Morris' status is founded on the aesthetic coordinates that have defined his work from the moment of his involvement in minimalism and land art-coordinates that have proved crucial to the transition sculpture has made from modernity to postmodernity- and on the unique nature of the new context in which he was invited to work, one characterised by a weighty cultural load of prehistoric origin and by the aesthetics of granite.

Keywords: Robert Morris, labyrinth, Pontevedra, land art

Como expresión de una estructura no monumental, Robert Morris (Kansas City, Missouri, 1931), uno de los artistas más complejos, profundos y plurales del último medio siglo, en lo que se refiere a su diversidad lingüística, siempre estuvo interesado en los laberintos porque no eran ni escultura ni arquitectura, sino, como nos recuerda Barbara Rose, una categoría existente a lo largo de la historia que hacía explícito uno de los grandes misterios ${ }^{1}$. Intuición de la crítica que tan bien lo conoce y fue la responsable comisarial de su última exposición en España², que el propio Morris avala y reafirma como una forma que va más allá de la memoria, el lugar imaginario que su admirado Wittgenstein ligó al lenguaje -considerando éste como un laberinto de senderos y que él reclama en la sutil paradoja de la pérdida y el reencuentro ("nos perdemos en el interior del laberinto, a fin de rencontrarnos") $)^{3}$.
Tal vez en pocas imágenes o iconografías, como la del laberinto, se ha podido resumir una filosofía tan densa y experimental, una reflexión estética acerca del tiempo y del espacio reales en relación al hombre -dimensionado desde el cuerpo- como la que ha hecho, en los últimos cincuenta años, Robert Morris.

En realidad, la citada versatilidad lingüística del artista, a lo largo de tantos años, ha seguido unos puntos de referencia constantes que comenzaron un día en el sistema all-overiano de Jackson Pollock, una de las recurrencias de su mágico cuarteto americano ${ }^{4}$, en la acción gestual de la pintura, su primer tiempo circular, a mediados de los cincuenta, y fueron madurando hasta hoy mismo entre tantos modelos que utilizó en un all-round corporal que expandía el sujeto, mental y físicamente, a una horizonta- 


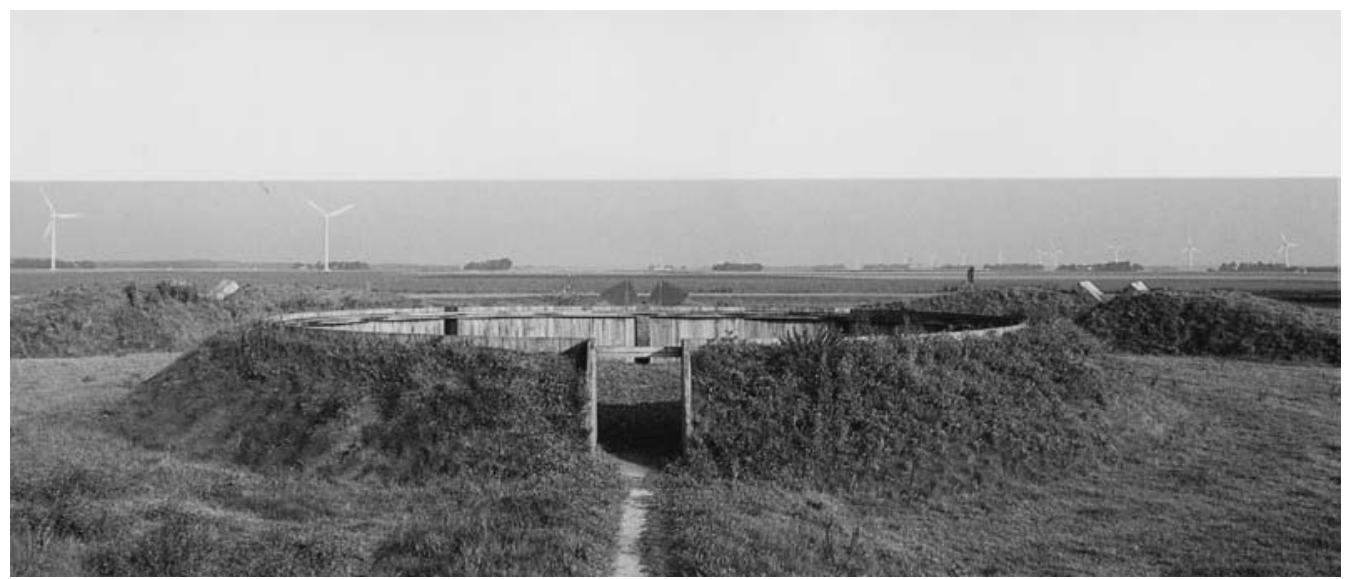

Robert Morris. Observatory, 1977. Oostelijk Flevoland. Ljssel-Zuider Zee. Holanda

lidad o a un vacío, vividos desde la verdadera percepción de la experiencia en movimiento.

Contra cualquier pronóstico, Morris no fue un minimalista al uso o, mejor aún, en el sentido estricto ni siquiera fue el minimalista que privilegió la ideación enajenada del sentido emocional: su rebeldía no le permitió ubicarse en el formalismo de aquellos años sesenta que enfriaron las estructuras del arte desde la fabricación y su misma conciencia anti-forma testimonia, tanto como sus posiciones estéticas multidireccionales, fuera del "campo único del lenguaje" - ¿y por qué no también por las posiciones éticas?-, cuan alejado estuvo siempre de ciertas tiranías modernistas 5 .

Cuando el artista sostiene que el arte ha sido siempre una fuerza particularmente autodestructiva, y el mejor ejemplo su continua capacidad de autodestruirse, tal como sucedió con

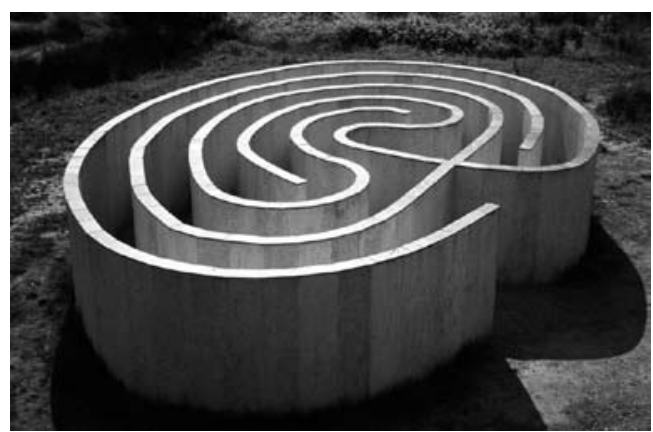

Robert Morris. Laberinto de Pontevedra, 1999 (2000 X 9000 X $12000 \mathrm{~cm}$.) Granito de Arcade y pizarra gris de Valdeorras la caída del modernismo, lo subsiguiente fueron un conjunto de reglas establecidas para racionalizar un procedimiento y un estilo de vida ${ }^{6}$. Frente a ellas ha reaccionado el hombre plural que se opuso a las propios dictados unívocos de su época, él, que fue capaz de explorar las opciones más sorprendentes que pudo arrancar al legado de Duchamp y nunca de una manera literal, avanzando la ruptura de la idea de género -tan definitoria su dilución en los últimos años del arte- que clasificase al artista como pintor o escultor, puesto que Morris transgredió los estatutos regulados de cada lenguaje específico en aras de posicionarse en un más allá que continuamente asocia el pensamiento y una reflexión intelectual (en su análisis de lector temprano y compulsivo son frecuentes, desde los inicios, las interpretaciones que emanan de los campos de la filosofía o de la psicología de la percepción y de pensadores como Wittgenstein MerleauPonty, Marcuse, Foucault o Davidson, por citar algún ejemplo) a la libertad y a la divergencia de

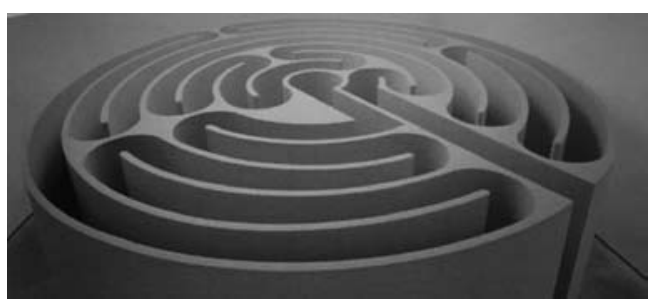

Robert Morris. Laberinto (Maqueta), Filadelfia.1974 


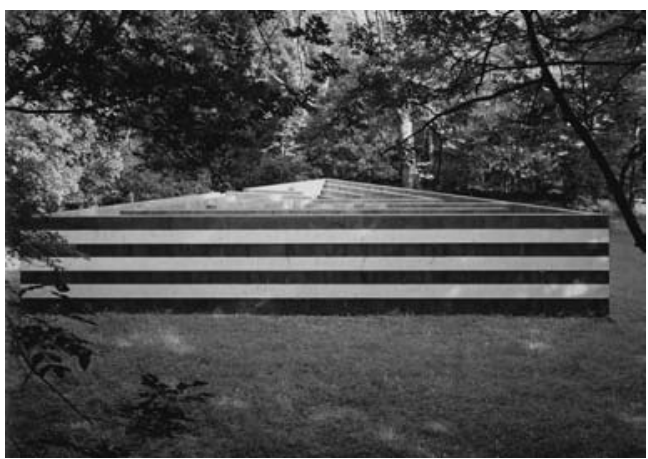

Robert Morris. Laberinto de la Fattoria di Celle. Santomato di Pistoia, Italia, 1982

sus realizaciones, que rompen la noción de estilo. Ello explica que del gesto pollockiano pasase a la danza, a la representación performántica, a la creación de peculiares coreografías y al teatro, que es la puesta en escena del "tiempo real", es decir, del presente que es su tiempo preferido, presencia que vuelve a implicar el cuerpo como medida, uno de los ejes fundamentales de su proyecto. Rebelión del cuerpo que es, al decir de Octavio Paz, también la de la imaginación ${ }^{7}$ y ambas rebeliones niegan el tiempo lineal, el del modernismo, para situarse en el ahora, en lo instantáneo, donde confluirían pasado y futuro. $Y$ ese cuerpo, que es camino hacia el presente, el del origen y el del ahora, prefigura la imagen iniciática del laberinto -la imagen ideal del presente continuo que elabora Morris-, el lugar del retorno ineludible, que nos lleva a vivir cara a la muerte y nos reconcilia con la realidad ${ }^{8}$.

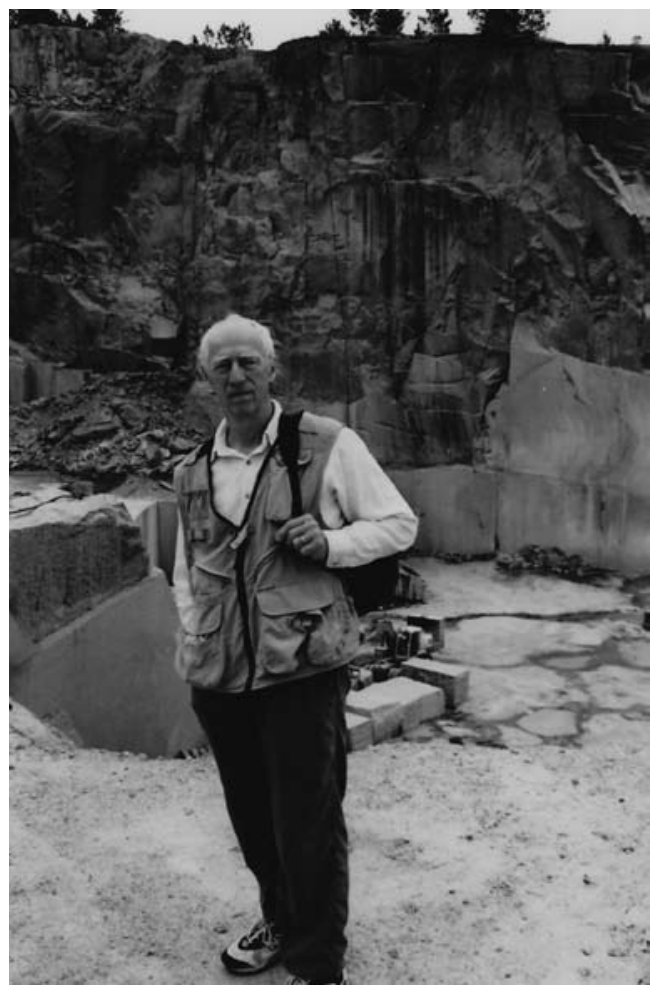

Robert Morris en las canteras de Porriño (Pontevedra), 1999

Pasar de ahí a las columnas, vigas o mesas y a las cajas, a la geometría arquitectónica de los objetos en contrachapado pintado, la imagen de la prefiguración minimalista, a principio de los sesenta, en coexistencia con los montajes sonoros, los filmes y las efímeras acciones con vapor,

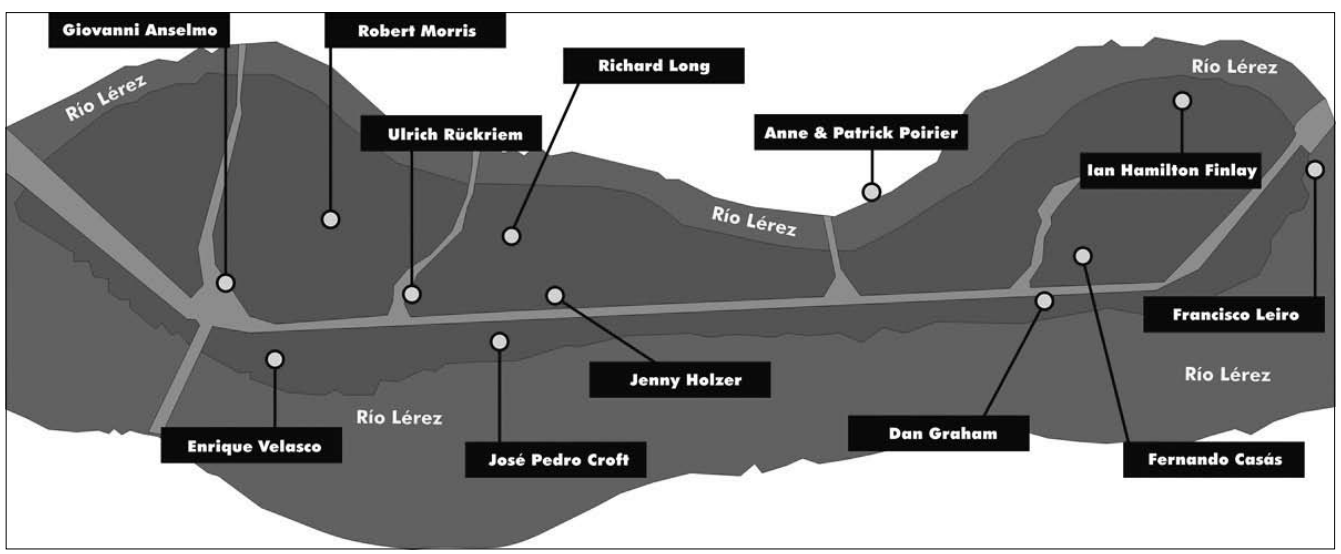

Plano de la Isla de Esculturas. Pontevedra 


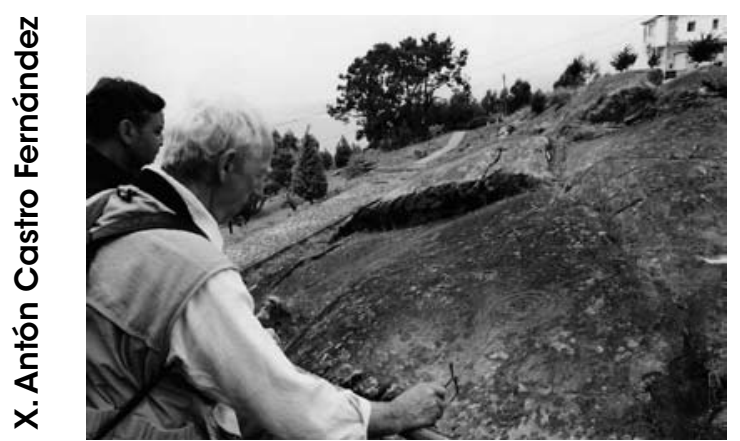

Robert Morris y Antón Castro analizando el Laberinto de Mogor (Marín-Pontevedra), 1999

o la incorporación del fieltro o de los espejos, no implicaba tampoco eludir la imagen del cuerpo, medida o expansión ficcional del mismo en el espacio, prolongando el vacío, tal como queda de manifiesto en Box for standing o Pine portal with mirrors.

Las diferentes ubicaciones o situaciones de las ya clásicas $L$ - beams (vigas en forma de L) o Columns (columnas), sus obras más asimilables al minimalismo de la primera mitad de los sesenta, aludían a una significación ligada estrechamente al cuerpo, a sus movimientos y a sus gestos, tal como defiende Rosalind Krauss" una de las más decisivas estudiosas del artista de Kansas City, que llegó a reforzar con un título no menos enfático, en relación a aquellos conceptos, su gran exposición antológica en el Guggenheim Museum de New York, en 1994: El problema cuerpo/espíritu.

Y por curioso que pueda parecer, en el origen de las referencias de sus columnas minimalistas, asistimos igualmente a la elaboración de la

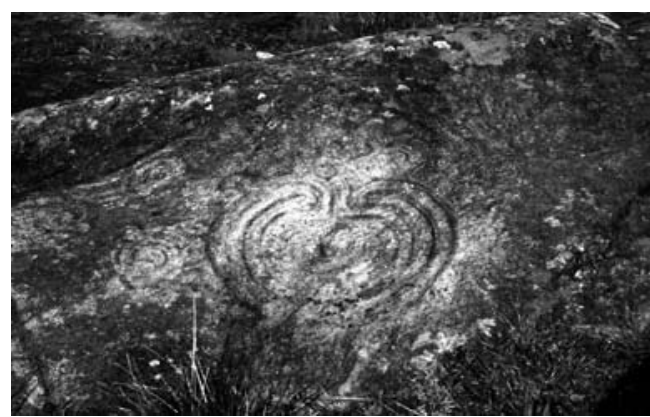

Laberinto de Mogor (San Xurxo do Monte, Marín, Pontevedra) idea de memoria (en este caso la pirámide egipcia de Sakarah), una mirada siempre presente en el Morris más jazz-man, investigador profundamente reflexivo e inventor de imágenes o de situaciones sorprendentes, que nunca ha dejado de observar e incluso de estudiar determinados pasados y de amar la historia: no es anecdótico que un punto de arranque o de encuentro con la memoria de la que jamás ha disidido, sea la que se hace presente en buena parte de su obra de las últimas décadas, desde los earthworks, sus trabajos en la naturaleza o con una cierta naturaleza, a partir de la segunda mitad de los sesenta, hasta sus series más comprometidas ${ }^{10}$, después de los setenta.

En estas últimas -dibujos, pinturas o relievesacude a complejas escenografías barrocas, cuyos mejores modelos son las hypnerotomachias -sueños de amor y de lucha-, que relatan accidentes, destrucciones, bombardeos, catástrofes, el Apocalipsis, la devastación nuclear, el holocausto, la imagen terrible de la guerra..., lo que Donald Kuspit definió como la "representación del drama y de la muerte", a la vez que optaba por posiciones que no eludían lo decorativo.

A este respecto, el mismo Morris ha explicado, en algún momento, sus intenciones, acudiendo a un binomio tan clásico como actual a la hora de situar los trabajos citados: "si la atracción por eso que es energéticamente abstracto podría ser asimilado a Eros, lo decorativo habría que situarlo del lado de Thánatos"11. Que es, en realidad, la filosofía de los reciclajes imaginarios postreros de su obra, citaciones en las que recrea, por ejemplo, a Cezanne, o autocitaciones, en las que asistimos a la interpretación de sus

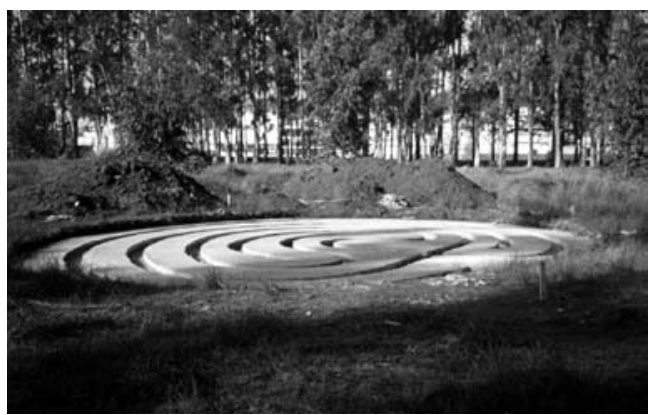

Robert Morris. Infraestructura del Laberinto de Pontevedra 


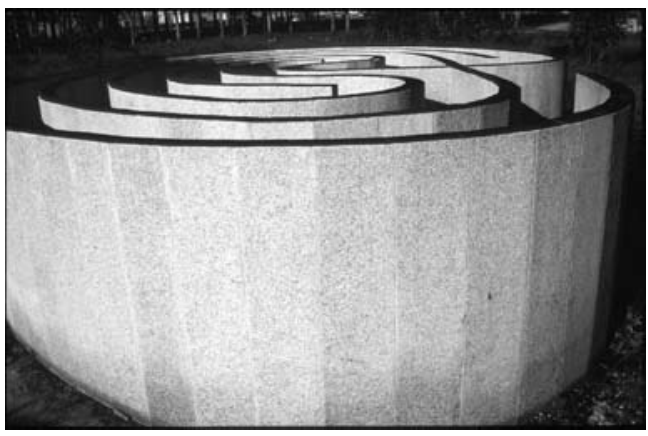

Robert Morris. Laberinto de Pontevedra

hilos conductores de siempre, como sucedía con The Rationed Years 1998, An Installation en la Galería Leo Castelli, a finales de 1998.

Sin embargo, nada de todo lo expuesto se aparta de la filosofía esencial de Morris, que encuentra en las imágenes o en las construcciones de la naturaleza y, por supuesto, en los laberintos, uno de sus recursos ideales para reflexionar en torno al tiempo, al pasado, a la memoria, a la experiencia perceptiva y al movimiento del espectador como sujeto activo que recorre su obra, escenificando en un particular all-round, una vez superada la idea de la representación pollockiana, la vivencia real del tiempo, de los sonidos, de los sentidos y aún de la propia autoconciencia. Su naturaleza, una naturaleza próxima a los núcleos urbanos, que es la que prefiere el artista, y no desértica -la de los land más puristas-, con los que compartía estrechas relaciones y amistad, como sucedía con Robert Smithson y Nacy Holt, tampoco se implicaba en el contestatarismo ideológicamente estético de

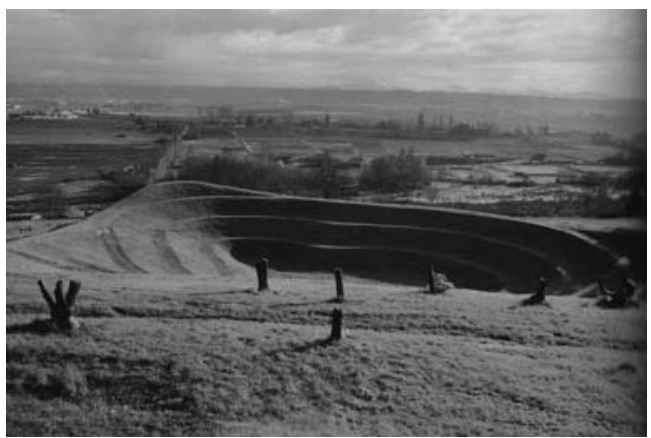

Robert Morris. Sin título, 1979. King Kounty, Washington

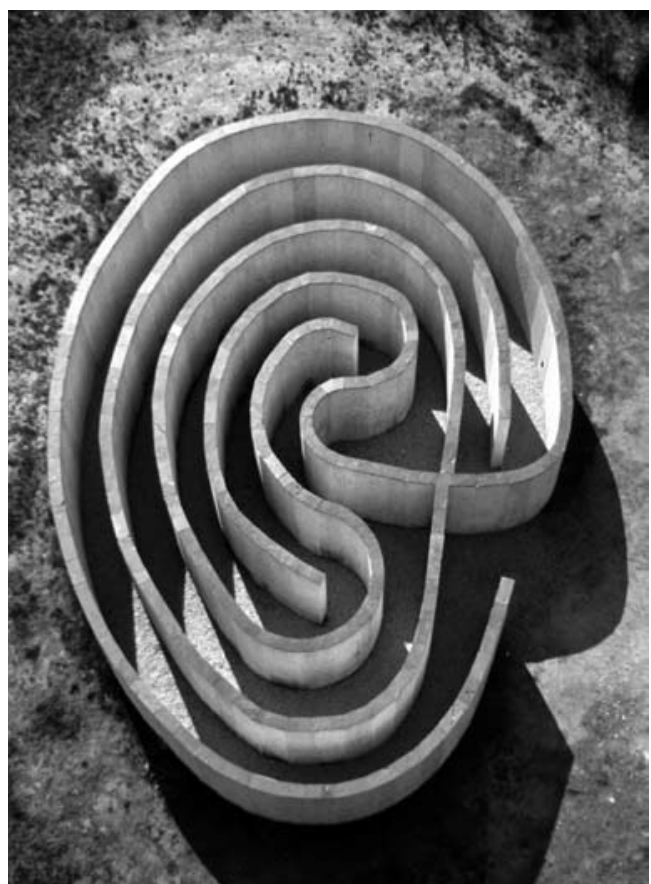

Robert Morris. Laberinto de Pontevedra. Vista aérea

la época. Sus earthworks se asimilan más a una idea de reflexividad que tiene en cuenta la propia historia -la primera referencia de Sakarah no es gratuita- aún pensando en la dinámica arquitectónica e integradora a unos sites que estudia meticulosamente en relación a todas las coordenadas posibles del paisaje.

Muestra de ello es que cuando se refiere a su primera gran obra de referencia en la naturaleza, el Observatory que había hecho para Sonsbeek '71, en Holanda, en el catálogo ("Observations on the Observatory"), dice que su trabajo "está más próximo en su esencia a los conjuntos arquitectónicos neolíticos u orientales" y así sucedía también, por ejemplo, con la instalación efímera que había hecho para la Documenta VI de Kassel, de 1977, una construcción de rocas de granito y basalto.

Pontevedra Labyrinth, como él lo tituló, o el Laberinto de Pontevedra es, tal vez, la culminación de su larga experiencia en torno a esta iconografía y otras semejantes, entre círculos y espirales, que ya fueron símbolos de las viejas culturas prehistóricas o históricas: desde Mo- 


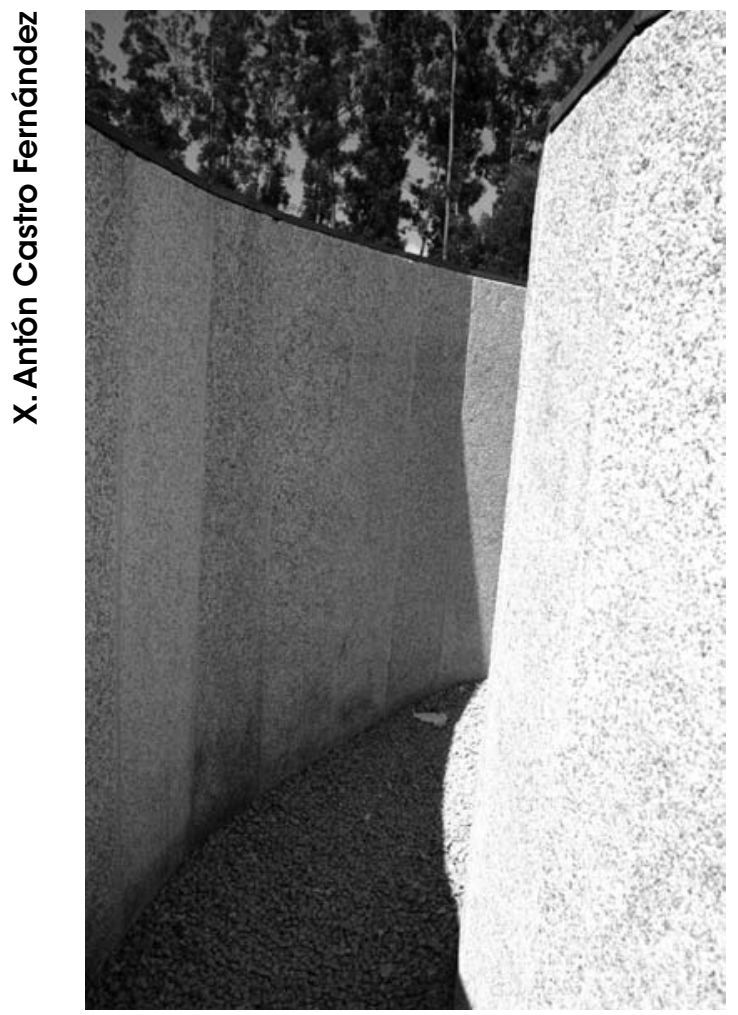

Robert Morris. Laberinto de Pontevedra. Detalle

del, un círculo de tierra y fuego que propuso, en 1966, para el aeropuerto regional de Dallas, jamás ejecutado, hasta el Ottawa Project -para el Parque Jacques Cartier de Ottawa-, en 1970, una rampa en espiral, sus singulares earthworks se fueron sucediendo, realizados o no, ejemplificados también en la representación expositiva sobre el papel u ofertados como gigantescas maquetas: dibujos a tinta de laberintos que se suceden, a partir de 1973, con las más diversas formas geométricas que elabora utilizando las proyecciones axonométricas -Untitled (Circular Labyrinth, 1973); exposiciones como LabyrinthsVoice-Blind-Time, en las galerías Castelli y Sonnabend ${ }^{12}$, de New York (1974), donde imagina tipologías romboidales, de círculos fragmentados, evocadoras del circo romano o de los mosaicos; proyectos como el Untitled (Philadelphia Labyrinth) (1974), sin duda el más borgiano e intrincado de sus laberintos, en contrachapado gris y masonita, realmente gigantesco para ser expuesto como maqueta, pues tenía un diámetro de más de 9 metros y una altura de 244 centímetros, para el que se había inspirado en la Catedral gótica francesa de Chartres ${ }^{13}$.

En 1982 inaugura su primer laberinto construido permanentemente, en la Fattoría di Celle, en Santomato (Pistoia-Italia), uno de los más reconocidos parques escultóricos de Europa, de planta triangular -sus lados miden 12 metros de largo por una altura de 2 metros-, en hormigón y mármol verde y blanco, cuya policromía alude al marco renacentista del baptisterio de Florencia, modelo de una perfecta adecuación al site físico y al entorno cultural.

En 1984 vuelve al modelo triangular de laberinto en la colectiva Content: A Contemporary Focus $1974-1984^{14}$ y, en 1990, su serie de dibujos Investigations, auténtico ensamblaje de imágenes y de citaciones, de revisitas a la historia del arte, es un retorno a la calle y a su propia historia artística, partiendo del modelo de las Investigaciones filosóficas de Wittgenstein: centro de su reflexividad y origen del título.

El laberinto es el símbolo que Maurice Berger incluye, un año antes, como parte fundamental de la identidad estética del artista, en la primera monografía consagrada a él: Labyrinths: Robert Morris, Minimalism and the 1960's' $\mathrm{s}^{15}$. La más reciente de sus construcciones laberínticas, una estructura en madera de mil metros cuadrados, se ha exhibido en el Museo de Lyon, durante el verano de $1999^{16}$.

Cuando Robert Morris fue invitado a participar en 1999 en el proyecto Isla de Esculturas, que se estaba llevando a cabo en una isla fluvial de 7 hectáreas en la periferia de la ciudad de Pontevedra, como ideólogo y comisario del mismo, y después de arduas conversaciones con el propio Robert Morris, tuve en cuenta el profundo conocimiento que tenía el artista norteamericano acerca de los laberintos, pero también él se prestó a estudiar la referencia más antigua de esta figura en Occidente, que se encuentra a unos cuantos kilómetros de la ciudad -en San Xurxo do Monte, Marín-, el Laberinto de Mogor, un petroglifo que emblematiza la primera identidad cultural y estética del Noroeste atlántico gallego. Así, pues, estudió este aspecto, pero también la filosofía propia del proyecto que trataba 

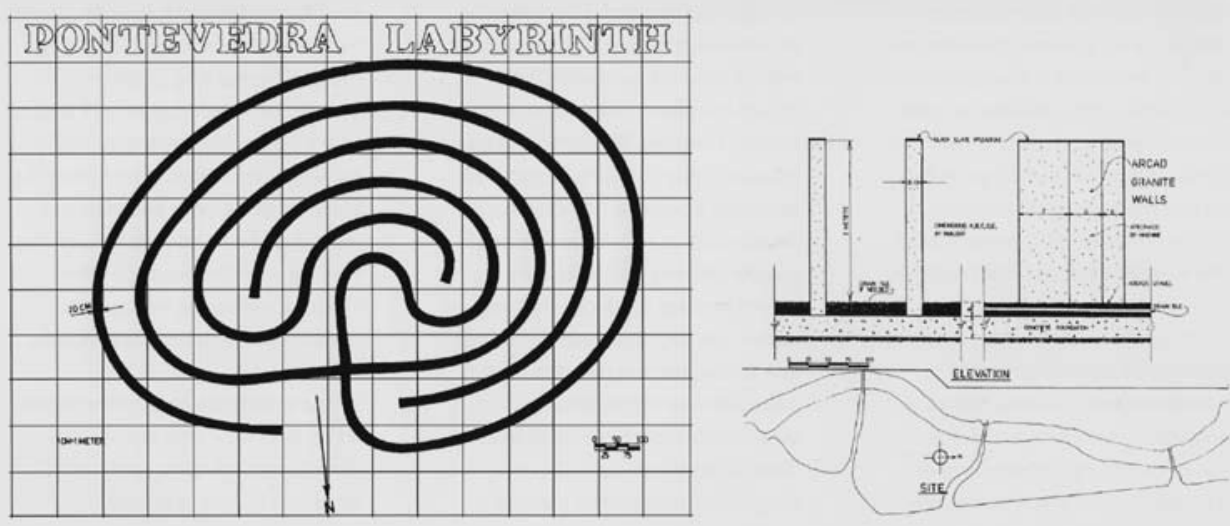

de elogiar al granito, la huella que ha marcado el arte, la etnografía y la antropología gallegas desde la prehistoria, a lo largo del románico y del barroco, tanto como las tradiciones, que aún persisten, de los canteros populares y la cultura de la piedra de una de las zonas que produce y exporta más este material al resto del planeta.

Así pues, Morris, tan interesado por este tema que ha sido uno de sus objetos mayores de reflexividad, no sólo ha estudiado documentalmente el Laberinto de Mogor, sino que lo ha hecho in situ y acudiendo a los mejores especialistas acerca del mismo, especialmente a Antonio de la Peña Santos, jefe del departamento de arqueología del Museo de Pontevedra y el más prestigioso investigador en el estudio de los petroglifos y del arte rupestre del Noroeste peninsular, que tuvo la deferencia de facilitar al artista una vastísima documentación sobre el petroglifo.

Su Pontevedra Labyrinth es, además de un homenaje a esa figura simbólica -el artista me comentaba informalmente, con su respetuoso humor, siempre comedido, que si el Laberinto de Mogor era el petrogifo más emblemático de finales del tercer milenio antes de Cristo, el suyo sería el Laberinto del final del segundo milenio después de Cristo-, enmarcada en la naturaleza granítica que define al país gallego en su antropología material, una reflexión madura en torno a las constantes que han marcado su trabajo, lejos, a mi entender, de las interpretaciones foucaultianas, a las que se refieren $\mathrm{M}$. Berger o D. Ottinger, entre otros, encaminadas a revelar su posición crítica respecto a la naturaleza represiva que se asocia ideológicamente al orden geométrico ${ }^{17}$, opción que el mismo Morris ha desmentido al que esto escribe.

Muy al contrario, su laberinto le hace retornar a la historia y a una memoria del tiempo, que es pensamiento e imaginación, cualidades proyectadas como experiencia del espacio físico, en una prolongación que discurre como presente continuo de la realidad que uno vive ${ }^{18}$. El trayecto que el espectador debe recorrer testimonia el deseo del creador, tal como hemos mencionado anteriormente, de permitir al cuerpo humano en movimiento una experiencia física, determinada por la estructura laberíntica, un caminar hacia lo desconocido, una experiencia que, al referirse a su Observatory, asocia a la influencia perfor-

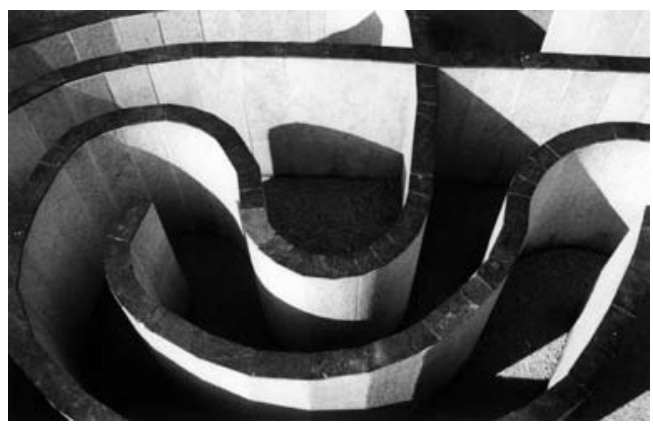

Robert Morris. Laberinto de Pontevedra. Detalle 


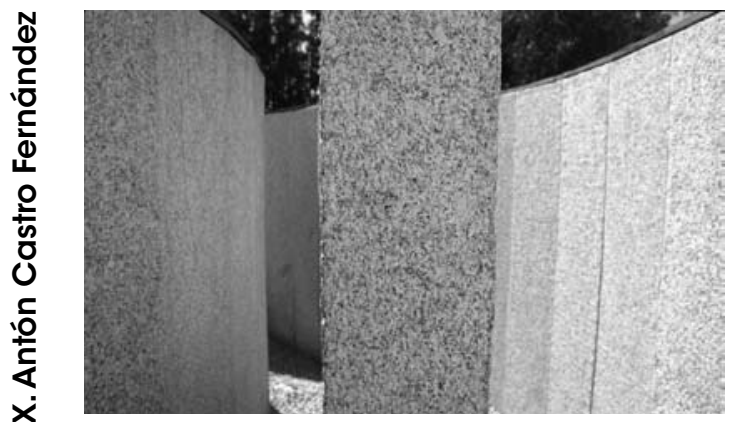

Robert Morris. Laberinto de Pontevedra. Detalle

mántica de Yves Klein: por su impulsión cósmica, pero también porque él "nos ha enseñado a utilizar el cuerpo como un útil para dejar una huella, un signo..." 19 .

Y quizás sea la citada obra el primer campo de operaciones reales -con sus trayectos, perspectivas y niveles en la gran estructura circular de 71 metros de diámetro- en el que ha conjuntado tales experiencias con su recurrente reclamo a la prehistoria megalítica o a la antigüedad oriental, maya o nazca ${ }^{20}$, especialmente en la reconstrucción que hace de la primera versión de Sonsbeek (Arhem), de 1971, en 1977, en Ljssel-Zuider Zee (Holanda), en un marco de alusiones alegóricas y de explicitud de la temporalidad estacional, a la manera de un nuevo Stonehenge, el cromlech británico con el que frecuentemente se ha relacionado este trabajo.

Morris ha volcado toda su sabiduría laberíntica en el modelo pontevedrés, estudiado meticulosamente como un proyecto milimétrico, a partir del grabado en piedra de Mogor: su obra es no sólo una interpretación libre de éste, una auténtica traducción ejecutable del cripticismo dibujístico del petroglifo, imagen de una utopía representacional de no sabemos qué, con certeza, ajustando la ideación imaginable de la prehistoria a la realidad, sino también un ejemplo de propuesta de ingeniería y de arquitectura experimentales. Y en función de ello ha cuidado la escala humana de sus medidas, ha introducido la dificultad de las irregularidades y estrechamientos o ensanchamientos de sus pasillos circulares, que fueron llevados a cabo escrupulosamente traduciendo el proyecto en el ordenador, para pasarlo posteriormente al site ${ }^{21}$.
Él mismo ha visitado las canteras para elegir finalmente el granito gris/blanco de Arcade, optando por la manera apiconada 22 , y la pizarra gris/negra de Valdeorras para coronar la parte superior del muro de piedra, a fin de resaltar el dibujo laberíntico desde una percepción más elevada, cuestión que ha solucionado con la proyección de una plataforma de madera, situada a unas quince metros de la obra. La construcción, de estructura circular, de dos metros de altura, que cruza dos diámetros desiguales de doce y de nueve metros, describiendo una superficie de más de cien metros cuadrados, asentada en el centro de una junquera baja, en relación al nivel medio de la isla, de unos cinco mil metros cuadrados de superficie, que encierra unos intrincados pasillos de entre cincuenta y ochenta centímetros, está orientada hacia el norte, que es donde se sitúa la entrada. Y si la escala se hace conscientemente humana es porque Morris rehuye de las piezas demasiado elevadas: éstas -piensa- empequeñecen al espectador, por lo cual acota su altura para reforzar el sentido de la horizontalidad ${ }^{23}$, porque el horizontal es el espacio del que dispone el cuerpo o, si se quiere, el vector del movimiento corporal, es, en definitiva, la escala propia del hombre ${ }^{24}$.

Como mito, el del laberinto se inscribe en la dimensión temporal que le atribuía Octavio Paz, puesto que su relación con el tiempo es peculiar, inscrito a la vez en la diacronía y en la sincronía, en tanto que lo afirma para negarlo: "cuenta una historia y se repite, se re-engendra, es tiempo que vuelve sobre si mismo, lo que pasó está pasando ahora y volverá a pasar" 25 . Imagen ideal del presente continuo de la filosofía de Robert Morris, que también huye de las interpretaciones certeras y lo considera un tema de controversia sin fin, reafirmando la experiencia del recorrido como un hecho subjetivo de cada uno de los espectadores ${ }^{26}$.

Desde Novalis a Borges el laberinto ha sido un enigmático sendero de sorprendentes poemas o relatos: en El Aleph, el escritor argentino reinventa varios, aunque el más clásico nace en las entrañas de la fábula cretense como la Casa de Asterión ${ }^{27}$, donde el monstruo, prisionero y relator en primera persona, habla de infinitas puertas ("Corro por las galerías de piedra hasta 


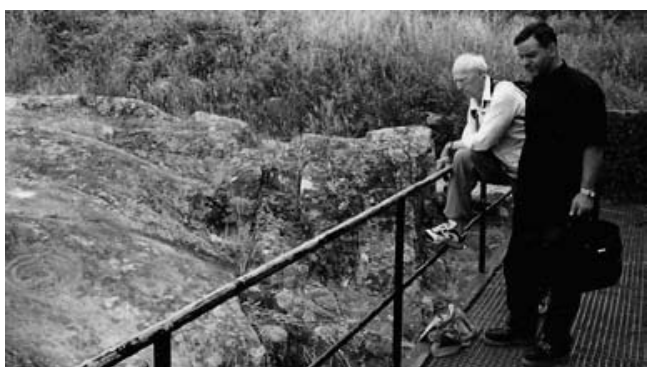

Robert Morris y Antón Castro observando el Laberinto de Mogor. Julio, 1999

rodar en el suelo, mareado(...)Todas las partes de la casa están muchas veces, cualquier lugar es otro lugar...") del templo de las Hachas y el mar, que se adscribían al primer laberinto.

Y son el mar y las relaciones marítimas, desde el tercer milenio antes de Cristo, los que hacen llegar la extraña figura, como símbolo de difíciles interpretaciones, a las partes más alejadas de la vieja cultura mediterránea. Juan-Eduardo Cirlot cita los cinco grandes laberintos a los que se refieren los textos antiguos: además de los cretenses de Knosos y Gortyna, fueron importantes el de Egipto, en el lago Moeris, el de la isla de Lemnos, en Grecia, y el etrusco de Clusium ${ }^{28}$. Pero como representación estética su difusión ha sido enorme desde entonces y es precisamente en Galicia, en la ría de Pontevedra, en el lugar de San Xurxo do Monte (Mogor, Marín), donde se encuentra la que quizás sea más antigua inscripción de un laberinto de Europa Occidental, fechado en la Edad del Bronce, entre finales del tercer milenio e inicios del segundo milenio antes de Cristo, como gran parte de los petroglifos o grabados en piedra, que aparecen a partir del período megalítico, huella permanente de las relaciones marítimas entre los diferentes países e incluso continentes.

El tantas veces citado Laberinto de Mogor, la inspiración de Morris, que el arqueólogo Antonio Blanco Freijeiro consideraba como el "tema arqueológico gallego de más renombre en el mundo científico" 29 , al igual que sucede con la mayoría de los laberintos, no responde a un significado preciso más allá de la pura especulación, pues en cada cultura ha podido tener simbologías diferentes ${ }^{30}$, aunque su imagen se suele ligar a la idea de un camino difícil hacia un centro sagrado, espacio al que aludiría, e incluso podría referirse a un ciclo de vida-muerte-vida, es decir, a un más allá donde se entra, se muere y se renace ${ }^{31}$.

El laberinto, en su origen y retorno -sabemos cuando entramos, pero no cuando saldremos, sin embargo la búsqueda del centro, primero, y de la salida, más tarde, son constantes- reubica a un sujeto o espectador en movimiento real que deviene la imagen de un continuum que fija, en el ahora, la historicidad cíclica, el momento y el tiempo de los mitos. Su sentido alegórico, que Morris había experimentado en obras anteriores, revitaliza igualmente la estructura de sus primeras interpretaciones de arquitecturas fabuladas, en las que el recuerdo logra fundir razón y pasión en un espacio de comportamiento que disocia la relación entre el yo y su prolongación reflejada como radiografía personal en el laberinto, cuyos dédalos, al decir, de Bárbara Rose, evocarían "las huellas líquidas, redobladas sobre ellas mismas, de los drippings de Pollock" 32 , aunque sin eximir cierto grado de escepticismo.

En uno de sus dibujos laberínticos de la serie Investigations (1990) se preguntaba Morris: "¿Puedo yo representar también la esperanza así? Dificilmente. ¿Y qué hacer de la creencia?"33. Preguntas que amplía cuando reflexiona en torno al laberinto de Lyon: ¿Los que penetran en el laberinto se preguntan, acaso, sobre el motivo de su propio recorrido en relación al tiempo y al espacio? ¿El laberinto nos propone un espacio o simplemente la posibilidad de escuchar un pasado anterior a todos los pasados conocidos? ${ }^{34}$.

En El mito del eterno retorno, Mircea Eliade asocia la búsqueda del centro, que es la zona de lo sagrado por excelencia, la de la realidad absoluta, a un camino complejo y lleno de dificultades, simbolizado en los extravíos en el laberinto, que no es más que el costoso sendero hacia el yo o la esencia de su ser, verdadero rito de paso sembrado de peligros, rito que nos permite, si logramos recorrerlo con fortuna, ir de lo efímero y de lo ilusorio a la realidad y a la eternidad, de la muerte a la vida, del hombre a la divinidad ${ }^{35}$.

El acceso al centro del laberinto equivaldría a una iniciación, donde a una existencia ayer profana e ilusoria le sucedería otra duradera y eficaz. 

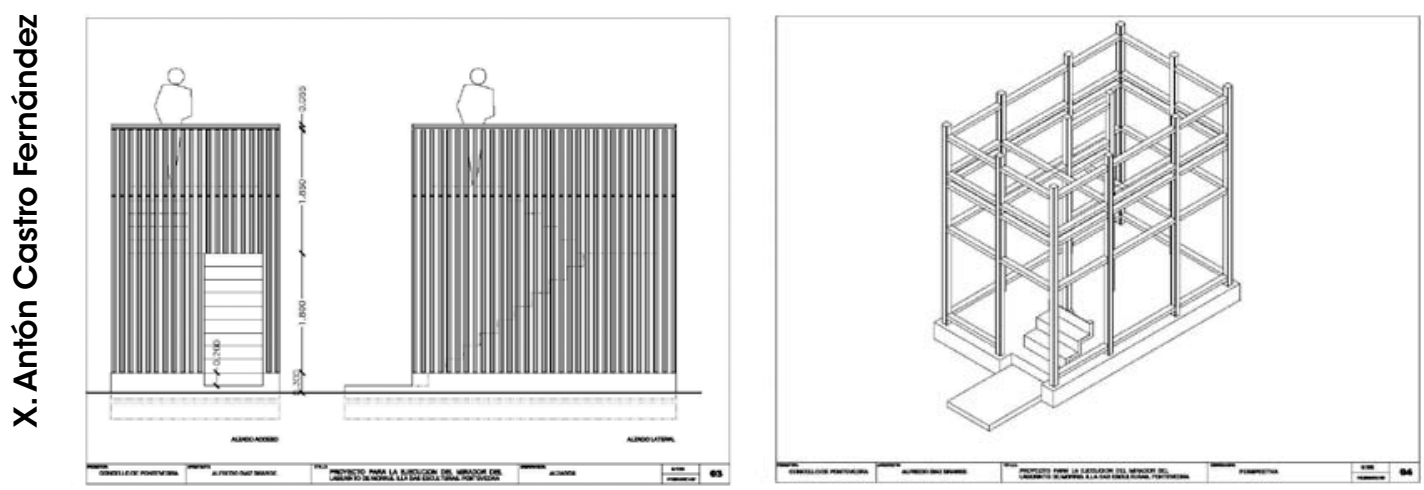

Proyecto del Mirador del Laberinto de Pontevedra, de Alfredo Díez Grande, según bocetos de Robert Morris, 2000

Imagen mítica de una esperanza que superaría el escepticismo, búsqueda del Grial de las fábulas ensambladas de Eliot que Morris dimensiona en el laberinto, a la manera de Borges, como una casa del tamaño del mundo, o, mejor dicho, como el mismo mundo. Sin embargo su construcción del paisaje laberíntico resulta también entrópico y unifica la fragmentación en la dimensión cíclica del espacio como imagen del único tiempo posible, que es el real, ese presente continuo ${ }^{36}$ que sitúa al hombre en un desplazamiento constante a la búsqueda de un imaginario Minotauro que difícilmente podrá encontrar. Fusión de tiempos y de espacios, porque, al contrario de lo que sucedía en sus L-Beams, de los años sesenta, el espacio de la experiencia, en el que aparece nuestro propio cuerpo, no "invalida las coordenadas axiomáticas de un espacio ideal" 37 .

Para que la construcción del laberinto superase la experiencia subjetiva del recorrido en la que el artista y el espectador pudiesen compartir las peculiares cualidades performánticas, el sentimiento de la danza y del movimiento, el sonido y el silencio o el fulgor de la resonancia ${ }^{38}$, Morris imaginó la posibilidad de la experiencia visual, vertebrada desde una Wiewing Platform (plataforma para ver o mirador) de unos tres metros y medio de altura, situada en una diagonal, trazada a quince metros de distancia de la obra, a fin de percibir el diseño laberíntico desde la altura, y la fiel reproducción reinterpretada del milenario petroglifo de Mogor con todas sus irregularidades. Sería una plataforma de madera, minimalista en su estructura, donde se ubicarían seis u ocho personas, según la propuesta del artista, que dio el visto bueno al proyecto del arquitecto pontevedrés Alfredo Díez Grande, intérprete de los bocetos diseñados previamente por Morris ${ }^{39}$. 
BIBLIOGRAFÍA

\section{a. Monografías/ Catálogos}

BERGER, M. (1989): Labyrinths: Robert Morris, Minimalism and the 1960's, New York, Harper and Row.

BLÁZQUEZ J. y LLULL LLOBERA, J. (2002): Proyectos de arte contemporáneo en espacios públicos, naturales y urbanos (España-Suecia-Italia). Proyecto Europeo "Cultura 2000". Cádiz, Fundación NMAC.

CASTRO, A. y OLIVARES, R. (1999): Isla de Esculturas. Illa da Xunqueira do Lérez-Pontevedra. Pontevedra-Madrid, Olivares y Asociados.

CASTRO, X.A. (2003): Illa das Esculturas. Pontevedra. Servicio de Publicaciones. Diputación de Pontevedra. Prólogos de Stefen Foster y César Antonio Molina.

CATÁLOGO. (1974): Robert Morris: Projects. Filadelfia, Institute of Contemporary Arts. Universidad de Pensilvania.

CATÁLOGO. (1984): Content: A Contemporary Focus 19741984. Washington D.C. , Hirshhorn Museum and Sculpture Garden, Smithsonian Institution.

CATÁlOGO. (1995): Robert Morris. París, Centro Georges Pompidou.

CATÁLOGO. (2000): Robert Morris. From Mnemosyne to Clio: The Mirror to the Labyrinth. Musée d'Art Contemporain de Lyon. Lyon-Milan, Skira/Seuil.

CATÁLOGO (2012). El hilo de Ariadna. Lectores/Navegantes. Casa del Lector. Madrid. Texto de Francisco Jarauta

DE LA PEÑA, A. Y VÁZQUEZ VARELA, J.M (1979):, Los petroglifos gallegos. Grabados rupestres prehistóricos al aire libre. A Coruña, Edicións do Castro. Sada-A Coruña.

GARRAUD, C. (2007): L'artiste contemporain et la nature. Parcs et Paysages européens. París, Éditions Hazan.

MORRIS, R. (1993): Continuous Project Altered Daily. Cambridge, Massachussets, Ed. MIT Press.

MORRIS, R., From Mnemosyne to Clio: The Mirror to the Labyrinth (1998-1999-2000). Musée d’Art Contemporain de Lyon. Skira/ Seuil, 2000.
W.AA. (2001): Art-Sites Spain. Contemporary Art + Architecture Handbook. San Francisco (USA), Sidra Stich.

VVA. (2006): Arte y naturaleza. Guía de Europa. Parques de Esculturas. Cádiz, Fundación NMAC /Madrid, Documenta Artes y Ciencias Visuales.

V.AA. (2011): Robert Morris. El dibujo como pensamiento. Valencia, IVAM. Institut d'Art Modern.

\section{b. Artículos de revista}

BLANCO FREIJEIRO, A. (1958): "El Laberinto de Mogor". Archivo Español de Arqueología, XXXI

CASTRO, X.A., Robert Morris: El Laberinto de Pontevedra. Lápiz, 165. Publicaciones de Estética y Pensamiento, S.L. Madrid, 2000, págs.. 31-39

FOSTER, St. (2000): "Isla de Esculturas". Art Notes, núm. 269. New York, 2000. P. 13

KRAUSS, R. (1973): "Sense and sensibility: Reflection on Post '60s". Artforum, vol.XII, 3: 48

KRAUSS, R . (1994): "Robert Morris. Autour du problème corps/esprit". Art Press, 193: 26, 29 y 31

MORRIS, R. (1978): "The Present Tense of Space". Art in America, febrero

MORRIS, R. (1980): "Notes on Art as/and Land Reclamation". October, 12: 101

MORRIS, R. (1981): "American Quartet". Art in America, diciembre: 93

MORRIS, R. (1975) "Aligned with Nazca". Artforum. Vol. XIV, 2: $26-39$

MORRIS, R. Professional Rules (Critical Inquiry, núm. 23, Invierno 1997. The University of Chicago. Chicago, 1997). Traducción: Lápiz, 165. Publicaciones de Estética y Pensamiento, S.L. Madrid, 2000, págs. 39-53

RUÍZ DE SAMANIEGO, A.(2000), Entrevista a Robert Morris. $A B C$ Cultural, 19-II. 


\section{NOTAS}

1 El dibujo como reflexión. En Robert Morris. El dibujo como pensamiento. IVAM. Valencia, 2011, p. 44

2 Robert Morris. El dibujo como pensamiento. IVAM. Valencia. 8 de septiembre, 2011-8 de enero, 2012.

${ }^{3}$ MORRIS, R., From Mnemosyne to Clio: The Mirror to the Labyrinth (1998-1999-2000). Musée d'Art contemporain de Lyon. Skira/ Seuil, 2000. Pp. 46 y 53

${ }^{4}$ MORRIS, R., "American Quartet". Art in America. New York, dic. 1981. Las otras figuras del cuarteto son Hopper, Duchamp y Cornell.

${ }^{5}$ En una reciente entrevista con Alberto Ruiz de Samaniego ( $A B C$. Madrid, 19-II-2000. Página de Cultura), Morris dice que nunca se vio a sí mismo como un minimalista, ese minimalismo que él cree que, al final, "se convirtió en una iglesia.

6 "Notes on Art as/and Land Reclamation". October, núm. 12. New York, primavera, 1980, p. 101.

${ }^{7}$ Los hijos del limo. Edit. Seix Barral. Barcelona, 1990, p. 219.

8 En Professional Rules (Critical Inquiry, núm. 23, Invierno 1997. The University of Chicago. Chicago, 1997), Morris hace, en primera persona, un desarrollo permenorizado de sus referencias y de lo que yo expongo anteriormente. El ensayo, a petición del que esto escribe, fue publicado por la revista Lápiz (número 165. Publicaciones de Estética y Pensamiento, S.L. Madrid, 2000, pp. 39-53) con el título Reglas profesionales. Ver igualmente MORRIS, R., From Mnemosyne to Clio..., cit., pp. 58 y ss.

9 "Sense and sensibility: Reflection on Post '60s". Artforum, vol.XII, núm. 3. New York, noviembre, 1973, p. 48 y "Robert Morris. Autour du problème corps/esprit». Art Press, núm. 193. Paris, julio-agosto, 1994, p. 26.

${ }_{10}$ Me refiero, en este caso, a la actitud más humana de Morris, al margen de su propio compromiso con los lenguajes, que ha sido total, sin hacer ningún tipo de concesión, que, aunque algunos sitúen, a partir de la muestra de sus obras de finales de los setenta y ochenta, ha existido siempre, incluso en los preludios del minimalismo: sólo así se explica una obra como Crisis, alegato contra el contra el conflicto de los misiles Cuba-Estados Unidos, en 1962, o su posterior repulsa y huelga contra el racismo o la protesta contra la Guerra de Vietnam, que le llevó a boicotear, junto con otros compañeros a la Bienal de Venecia de 1970. Aunque Robert Morris piensa que el arte ha sido siempre una forma de propaganda en beneficio de cualquier persona o de cualquier causa o cosa, también piensa que aquellos artistas que se dejan seducir por las motivaciones sociales son, a menudo, los que hacen peores obras

${ }^{11}$ American Quartet, cit., p. 93.

${ }^{12}$ La presentación de esta exposición se hizo con el famoso póster, que tanto escándalo causó entonces, en el que aparecía el artista con el torso desnudo, encadenado, con un casco del ejército alemán de la segunda guerra mundial y unas gafas de aviador

${ }^{13}$ Este laberinto se exhibió en la exposición Robert Morris: Projects. Institute of Contemporary Arts. Universidad de Pensilvania. Filadelfia (23 de marzo a 27 de abril, de 1974). Fue destruido después de la exposición y sus derechos de reconstrucción los adquirió el Conde Oanza di Biumo, el famoso coleccionista de Minimal Art.

${ }_{14}$ Hirshhorn Museum and Sculpture Garden, Smithsonian Institution. Washington D.C. (4 de octubre, de 1984-6 de enero de 1985). 1989.

15 Harper and Row. New York,

${ }^{16}$ Vid. MORRIS, R., From Mnemosyne to Clio...., cit. El libro se editó con motivo de la muestra, cuya centralidad era el Labyrinth de $200 \mathrm{~cm}$. de alto, al igual que el de Pontevedra, y un desarrollo circular de $32.3000 \mathrm{~cm}$.

17 "Apocalyse now?". In Robert Morris. Centro Georges Pompidou. París, 1995, p. 37. De Berger ya hemos citado su libro. Tal vez estas interpretaciones se han hecho a raíz de la influencia que el libro de M. Foucault, Surveiller et punir: la naissance de la prison (vigilar y castigar: el nacimiento de la prisión), ha tenido en Morris, cuya relación parece clara en su artículo de Art in America (febrero de 1978), "The Present Tense of Space" $y$, a partir de ahí en su serie de dibujos In the Realm of the Carceral, que pone de manifiesto la relación histórica entre cierta geometría y las estructuras de represión, tal como describe Foucault, evocando la arquitectura carcelaria.

${ }^{18}$ Robert Morris habla de este concepto en su libro Continuous Project Altered Daily. Ed. MIT Press. Cambridge, Massachussets, 1993.

${ }^{19}$ KRAUSS, R., "Robert Morris: Autour du problème corps/esprit", cit., p. 31.

${ }^{20}$ MORRIS, R., "Aligned with Nazca". Artforum. Vol. XIV, núm. 2. New York, octbre, 1975, pp. 26-39.

21 En la memoria del proyecto, que él ha seguido con mimo, Morris, no ha descuidado ningún detalle, desde la elección del tipo de piedra (con el consiguiente desplazamiento a las canteras), grava o pizarra, a la disposición y naturelza de los muros, modos de cimentación y de picado de piedra, disposición del interior, sistema de canalización del agua, modelo recomendable de trabajo, tratamiento del site y condiciones de mantenimiento.

22 Un modo de abujardado dulce, es decir, el granito trabajado con una rugosidad suave y uniforme.

${ }^{23}$ Entrevista con Alberto Ruiz de Samaniego, cit.

${ }^{24}$ KRAUSS, R., Robert Morris. Autour..., cit., p.29.

${ }^{25}$ Levi Strauss o el nuevo festín de Esopo. Edit. Seix Barral. Barcelona, 1993, p. 56.

${ }^{26}$ MORRIS, R., From Mnemosyne to Clio..., cit., p. 47

27 El Aleph. Alianza/Emecé. Madrid, Buenos Aires, 1989, p.69.

28 Diccionario de símbolos. Edit. Lábor. S.A. Barcelona, 1985, p. 265.

${ }^{29}$ Arqueología gallega. El Museo de Pontevedra. Pontevedra, 1998, pág. 386. Puede verse su completísimo estudio "El Laberinto de Mogor" en Archivo Español de Arqueología, XXXI. Madrid, 1958. José M. Blázquez considera que Blanco Freijeiro ha sido uno de los grandes arqueólogos de la Arqueología Clásica del presente siglo en España. Cit., pág. 13. La bibliografía del Labeinto de Mogor es amplísima y ha sido tratado por buena parte de la 
comunidad científica internacional, estudiosa del arte rupestre.

30 DE LA PEÑA, A. Y VÁZQUEZ VARELA, J.M., Los petroglifos gallegos. Grabados rupestres prehistóricos al aire libre. Edicións do Castro. Sada-A Coruña, 1979, p. 39.

${ }^{31}$ Arqueología gallega, cit., p. 389.

32 "L'odysée de Robert Morris". En Robert Morris, cit. , p. 174.

${ }^{33}$ Could $i$ also represent hope in this way? Hardly. And what about belief?
${ }^{34}$ MORRIS, R., From Mnemosyne to Clio..., cit., p. 52

35 Planeta Agostini. Barcelona, 1984, p. 23.

${ }^{36}$ Véase MORRIS, R. Continuous Project Altered Daily. MIT Press. Cambridge, Massachussets, 1993.

${ }^{37}$ KRAUSS, R., "Sense and sensibility...", cit., p. 48.

${ }^{38}$ MORRIS, R., From Mnemosyne to Clio..., cit., pp. 46-53

39 En diferentes cartas (fechadas el 9 de abril, 12 de abril, 19 de Julio,
28 de agosto y 6 de octubre, de 2000) enviadas por Morris al que esto subscribe, da instrucciones de cómo quiere que sea el mirador (Wiewing Platform) y de la necesidad de construirlo para completar su proyecto. Después de haber obtenido el presupuesto necesario de la Subdirección General de Museos de la Dirección General de Bellas Artes y Bienes Culturales del Ministerio de Cultura, en 2007 y 2009, el Ayuntamiento de Pontevedra, se inhibió de la construcción de la misma, sin aportar ningún tipo de explicación. 